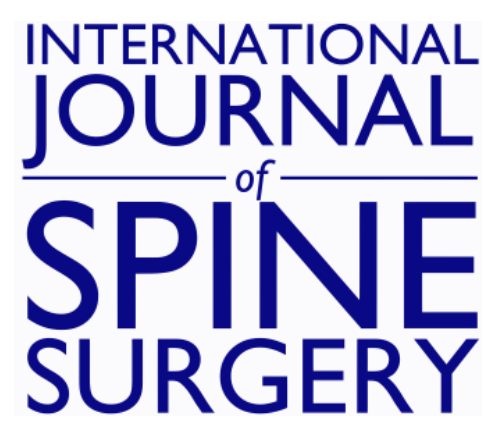

\title{
Surgical Management of Multiple Myeloma With Symptomatic Involvement of the Spine
}

HELENA MILAVEC, NIVETHA RAVIKUMAR, NICHOLAS L. SYN, CINNIE YENTIA SOEKOJO, WEE JOO CHNG and NARESH KUMAR

Int J Spine Surg 2020, 14 (5) 785-794

doi: https://doi.org/10.14444/7112

http://ijssurgery.com/content/14/5/785

This information is current as of April 26, 2023.

Email Alerts Receive free email-alerts when new articles cite this article. Sign up at: http://ijssurgery.com/alerts 


\title{
Surgical Management of Multiple Myeloma With Symptomatic Involvement of the Spine
}

\author{
HELENA MILAVEC, Dr Med, ${ }^{1,2}$ NIVETHA RAVIKUMAR, MBBS, ${ }^{1}$ NICHOLAS L. SYN, GCSE A-Levels, ${ }^{3}$ \\ CINNIE YENTIA SOEKOJO, MD, MRCP(UK) ${ }^{4}$ WEE JOO CHNG, MBBS, PhD, ${ }^{4}$ NARESH KUMAR, MBBS, \\ MS (Orth), DNB (Orth), DM (Spine) $)^{1}$ \\ ${ }^{I}$ Department of Orthopaedic Surgery, National University Health System, Singapore, ${ }^{2}$ Department of Orthopaedic Surgery and Traumatology, Spine Unit, \\ Inselspital, Bern University Hospital, Bern, Switzerland, ${ }^{3}$ Yong Loo Lin School of Medicine, National University of Singapore, Singapore, ${ }^{4}$ Department of \\ Haematology-Oncology, National University Health System, Singapore
}

\begin{abstract}
Introduction: Multiple myeloma (MM) is the most frequent primary malignancy of the spine. We aimed to investigate the clinical presentation, surgical indications and outcomes, complications, survival, and its influencing factors in surgically treated MM patients with symptomatic involvement of the spine (SIS).

Methods: Retrospective analysis of prospectively collected data. Out of $350 \mathrm{MM}$ patients treated at our institution over a period of 12 years (2006-2018), we identified 24 patients who were surgically treated for SIS. We collected data on demographics, clinical presentation, comorbidities, surgical indications, and outcomes and investigated the factors predisposing to postoperative complications and survival.

Results: The median follow-up duration was 85 months; median overall survival (OS) was 50 months. Clinical presentation at admission included pain (88\%), sensory and/or motor deficit $(67 \%)$, and bowel/bladder dysfunction $(25 \%)$. Symptomatic pathological fractures were seen in $33 \%$. Predominant surgical indications were rapid neurological deterioration with or without spinal cord compression (SCC), followed by mechanical instability. The majority of our patients benefited from surgery in terms of pain reduction in the short term as well as in the long term. There were $21 \%$ patients with surgical-related complications ( $<3$ months). Surgical site infections occurred in $17 \%$, without any obvious factors predisposing to infective complications. Neurological deterioration during hospital stay, especially in the presence of motor deficit and/or bowel/bladder dysfunction, significantly reduced OS.

Conclusions: Sudden-onset neurological deterioration was the predominant factor leading to surgery. We achieved good short- and long-term pain reduction. Surgery is a valuable option for MM patients with SIS who present with rapid neurological deterioration with or without SCC and/or mechanical instability.
\end{abstract}

Tumor

Keywords: multiple myeloma, spine, pathological fractures, neurologic deficits, spinal cord compression, surgery, pain, complications, infections, functional outcomes, overall survival

\section{INTRODUCTION}

Multiple myeloma (MM) is a systemic lymphoproliferative neoplasm with the accumulation of abnormal plasma cells in the bone marrow. ${ }^{1,2} \mathrm{MM}$ is diagnosed at a median age of 69 years $^{3}$ and currently has an incidence of 6.6 cases per 100,000 population, which is expected to increase in the future. ${ }^{3}$ Spinal involvement is common and affects approximately $70 \%$ of $\mathrm{MM}$ patients, ${ }^{4,5}$ thereby rendering it the most frequent primary cancer of the adult spine. ${ }^{6,7}$

The development of progressive and destructive osteolytic bone lesions ${ }^{1,8-10}$ may lead to pathological fractures, which are present in $>50 \%$ of all myeloma patients, ${ }^{11}$ further leading to spinal instability. ${ }^{8,12,13}$ Moreover, epidural involvement due to tumor mass or spinal instability implies a high risk of neurological compromise. ${ }^{14-18}$ Spinal cord compression (SCC) affects approximately 10\% of all myeloma patients. ${ }^{19}$ These features considerably reduce patients' quality of life and their independence. $^{20-22}$

Therapeutic advancements have effectively increased the progression free survival and have led to a current 10 -year survival rate of up to $30 \%-40 \%{ }^{23}$ MM is usually managed with a multidisciplinary approach, ${ }^{16,18,21}$ where a combination of drugs, including proteasome inhibitor, immunomodulatory drugs, and steroids, are the mainstay of treatment. In eligible patients, consolidation with high-dose chemotherapy (ChT) followed by autol- 
ogous stem cell transplantation (ASCT) is common. ${ }^{23}$ Spinal lesions, if symptomatic, are treated mostly by a combination of low-dose radiotherapy (RT), antimyeloma drugs (AMD), and bisphosphonates. ${ }^{4,18,24}$ According to the NOMS framework, the decision for surgery is based on the neurological status (myelopathy, degree of epidural SCC), radio/ chemo-sensitivity of tumor, mechanical instability, and the extent of systemic disease and medical comorbidities. $^{25}$ There is corroborative evidence in the literature that surgical management of $\mathrm{MM}$ leads to significant improvements in patients' neurological status ${ }^{6,16,26,27}$ and quality of life. ${ }^{6,24,28}$ However, the definite role of possible local treatments, such as vertebroplasty/kyphoplasty, RT, ${ }^{9}$ or open/minimally invasive surgery, in the management of myeloma-related spinal lesions remains unclear. ${ }^{9,27}$ Furthermore, in patients without neurological compromise, the role of surgery is debateable. ${ }^{9}$ It is vital to ensure that the benefits of surgical management prevail over its perils since these patients are highly susceptible to infections and exhibit poor bone quality. ${ }^{29-31}$

In our study, we aimed to investigate clinical presentation, main indications leading to surgery, functional outcomes, complications ( $\leq 3$ months postoperatively), and factors influencing neurological deterioration (during hospital stay), infective complications, and overall survival (OS) of MM patients with symptomatic involvement of the spine (SIS) in our population.

\section{METHODS}

We retrospectively reviewed prospectively collected data of MM patients who underwent surgery for SIS at a single tertiary care institution between 2006 and 2018. The National Healthcare Group Domain Specific Review Board approval was obtained before commencement of this study. All patients' data were accessed through the hospital electronic records (Computerized Patient Support System-2 [CPSS-2]). Where fractions are reported, the denominators reflect the total number of patients with non-missing observations.

\section{Data Collection}

We collected the following data: demographics, epidemiology, MM Revised International Staging System (R-ISS) stage, Spinal Instability Neoplastic Score (SINS), survival prediction scores, treatment modalities, surgical details, pain (visual analogue scale [VAS]), functional outcomes and performance status, complications and implant/construct failure, OS, and possibly influencing factors. The number of vertebral levels involved, the presence or absence of pathological fractures, and implant/construct failure were determined from the available serial radiographs.

\section{Study Criteria}

All patients included in our study were diagnosed with MM with SIS on histological confirmation of samples from bone marrow and/or tumor biopsy. The patient data were accessed at admission, at discharge from the hospital, and then at yearly intervals until the last available follow-up visit or death, whichever occurred first. Implant/construct failure was defined as screw loosening, construct breakage, or loss of spinal correction. ${ }^{27}$ We studied the overall complications within 3 months after surgery and focused on implant failure, tumor recurrence, and revision over a period of 12 months following surgery. SCC was defined as grades 2 and 3 , according to the Bilsky grading scale. ${ }^{32} \mathrm{We}$ defined mechanical instability in cases where SINS $\geq 7$ in combination with moderate to severe mechanical pain. ${ }^{33}$

\section{Outcome Measures}

\section{Pain}

VAS was classified as none, mild, moderate, and severe pain. Any increase or decrease in VAS from baseline was considered as pain reduction or failure of pain control, respectively.

\section{Functional Outcome}

Patients whose ambulation and neurological status were preserved or restored after surgery (Eastern Cooperative Oncology Group [ECOG] 1-2 or American Spinal Injury Association [ASIA] D-E, respectively), were considered to have a positive functional outcome.

\section{Spinal Stability}

Spinal stability was classified according to SINS. ${ }^{33}$

\section{Morbidity}

Preoperative comorbidities were graded according to the Charlson Comorbidity Index (CCI). 


\section{OS}

Calculated from the date of surgery until death or censored at the time of last follow-up.

\section{Statistical Analyses}

Continuous data are presented as mean \pm SD if normally distributed (based on the Shapiro-Wilk test); otherwise, the medians (interquartile range [IQR]) are presented. Paired $t$ tests were used to compare pre- and postoperative outcomes for normally distributed continuous outcomes. Wilcoxon's signed-rank test was used to compare pre- and postoperative outcomes for ordinal scales (eg, recoded VAS, ASIA score, ECOG score); pain scores were analyzed as an ordinal scale. Ordinal scales were analyzed as continuous variables in regression analyses. Because of the small sample size, only univariable regression was conducted. Linear regression and quartile regression (only when residuals were not normally distributed) were used to analyze continuous outcomes. Logistic regression was used to analyze dichotomous outcomes. Cox regression was used for survival analyses, and the proportional hazards assumption was verified by the Grambsch-Therneau method. Median follow-up time for OS was calculated using the reverse Kaplan-Meier method. Due to the exploratory nature of this analysis, a $P$ value $<.10$ was regarded to be indicative of a trend, while a $P$ value $<.05$ was taken to represent nominal statistical significance. All analyses were conducted in STATA (version 13.0) (StataCorp, College Station, Texas).

\section{RESULTS}

Out of 350 patients who were treated for MM at our tertiary care institution from 2006 to 2018, 24 underwent surgical treatment for SIS. The mean age of patients at the time of surgery was 59.3 (SD \pm 10.4); the male:female ratio was $3: 1$. The median follow-up was 85 months $(95 \%$ confidence interval [CI]: 13-118), with no loss of follow-up; median OS was 50 months (95\% CI: 18-124). The 1-year, 2year, 5-year, and 10-year survival rates in the overall cohort were $82.3 \%$ (95\% CI: 59.3\%-93.0\%), 69.1\% (95\% CI: $42.5 \%-85.2 \%), 38.4 \%$ (95\% CI: $14.8 \%-$ $61.9 \%$ ), and $30.7 \%$ (95\% CI: $9.9 \%-54.7 \%$ ), respectively (Figure 1). The demographics, clinical and laboratory findings, and tumor characteristics are described in Table 1.

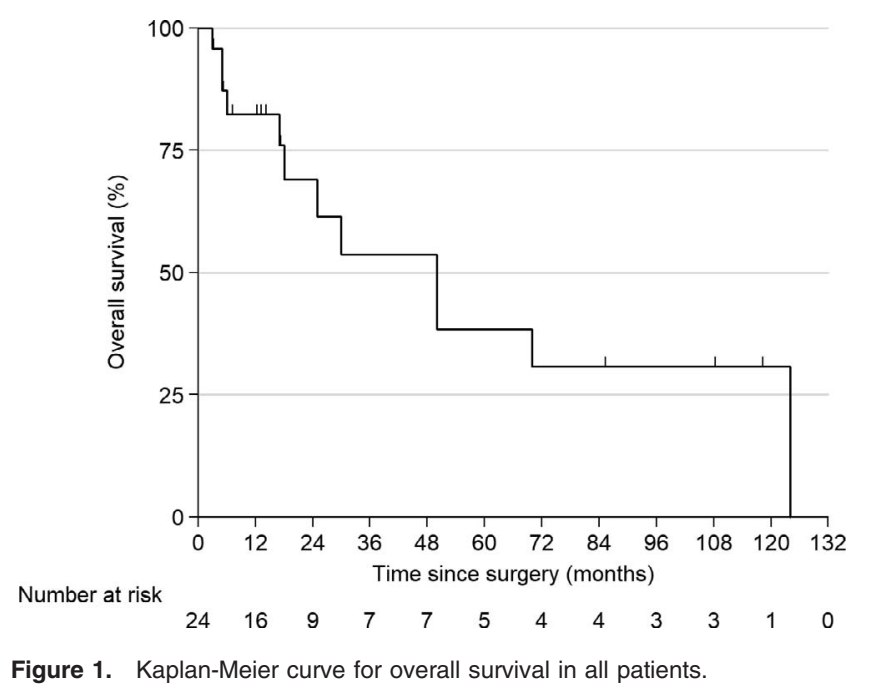

Spinal symptoms were the first clinical presentation of MM in $62 \%(15 / 24)$ of our patients (Table 2 ). The time duration from the onset of the first symptom indicating spinal involvement to the first consultation was 16 days (IQR: 4-60). Clinical presentation at admission included 1 or more of the following symptoms: pain in $88 \%(21 / 24)$ and $67 \%$ $(16 / 24)$ having sensory and/or motor deficit, including $25 \%(6 / 24)$ bowel/bladder dysfunction. On spine imaging, SCC was present in $71 \%(17 / 24)$ of patients, where $63 \%(15 / 24)$ had neurological deficit and $25 \%(6 / 24)$ presented with bowel/bladder dysfunction. Pathological fractures within the operated vertebral levels were present in $33 \%(8 / 24)$, where 2 of these fractures had led to neurological deficit as a result of SCC. Of 22 patients with available SINS data, 77\% (17/22) showed indeterminate instability (SINS 7-12) and 23\% (5/22) were unstable (SINS 13-18).

In patients who suffered from motor deficit and/or bowel/bladder dysfunction, the time duration from the onset of these symptoms to surgery was 8 days (IQR: $3-16)$. One-third (8/24) of our patients received postoperative RT within 8 weeks after surgery as an adjuvant therapy. All our patients received single-agent or multiagent AMD therapy.

\section{Surgical Indications and Intraoperative Details}

The predominant indication that had led to surgery was rapid neurological deterioration with or without SCC (61\% [14/23]) (Table 2). Mechanical instability was the main indication in 35\% (8/ 23), with SINS ranging between 9 and 13. Of these 8 patients, 3 suffered from moderate pain and 5 from 
Table 1. Patient demographics and baseline characteristics.

\begin{tabular}{|c|c|}
\hline Parameter & Value \\
\hline \multicolumn{2}{|l|}{ Demographics } \\
\hline Age, mean $\pm \mathrm{SD}, \mathrm{y}$ & $59.3 \pm 10.4$ \\
\hline Gender, male:female & $18: 6$ \\
\hline \multicolumn{2}{|l|}{ Ethnicity, no./total } \\
\hline Chinese & $19 / 24$ \\
\hline Malay & $2 / 24$ \\
\hline Others & $3 / 24$ \\
\hline Weight, mean $\pm \mathrm{SD}, \mathrm{kg}$ & $63.7 \pm 12.8$ \\
\hline Body mass index, mean $\pm \mathrm{SD}, \mathrm{kg} / \mathrm{m}^{2}$ & $23.8 \pm 4.4$ \\
\hline \multicolumn{2}{|l|}{ Functional status and comorbidities at admission } \\
\hline \multicolumn{2}{|l|}{ Eastern Cooperative Oncology Group score, no./total } \\
\hline 1 & $8 / 24$ \\
\hline 2 & $8 / 24$ \\
\hline 3 & $8 / 24$ \\
\hline Karnofsky Performance Scale, median (interquartile range [IQR]) & $60(50-80)$ \\
\hline \multicolumn{2}{|l|}{ American Spinal Injury Association grading, no./total } \\
\hline B & $1 / 24$ \\
\hline $\mathrm{C}$ & $4 / 24$ \\
\hline $\mathrm{D}$ & $11 / 24$ \\
\hline $\mathrm{E}$ & $8 / 24$ \\
\hline \multicolumn{2}{|l|}{ American Society of Anesthesiologists grading, no./total } \\
\hline 2 & $9 / 23$ \\
\hline 3 & $14 / 23$ \\
\hline Charlson Comorbidity Index, median (IQR) & $5(4-6)$ \\
\hline Diabetes, no./total & $4 / 24$ \\
\hline Tomita score, median (range) & $3(3-7)$ \\
\hline Tokuhashi score, median (range) & $7(2-10)$ \\
\hline Spinal Instability Neoplastic Score, median (IQR) & $11(10-12)$ \\
\hline \multicolumn{2}{|l|}{ Biochemical markers/full blood count/renal and liver panel preoperatively } \\
\hline Lactate dehydrogenase, mean $\pm \mathrm{SD}$ & $424.9 \pm 190.4$ (raised versus not raised) \\
\hline Calcium, mean $\pm \mathrm{SD}$ & $2.42 \pm 0.21$ \\
\hline \multicolumn{2}{|l|}{ Creatinine } \\
\hline Mean \pm SD & $150.0 \pm 200.0$ \\
\hline Median (IQR) & $96(66-121)$ \\
\hline Hemoglobin, mean $\pm \mathrm{SD}$ & $10.9 \pm 2.2$ \\
\hline White blood count, mean \pm SD & $7.6 \pm 3.5$ \\
\hline \multicolumn{2}{|l|}{$\begin{array}{l}\text { Platelets } \\
\text { Plo }\end{array}$} \\
\hline Mean $\pm \mathrm{SD}$ & $255.9 \pm 124.0$ \\
\hline Median (IQR) & $219(182-338)$ \\
\hline \multicolumn{2}{|l|}{ Albumin } \\
\hline Mean \pm SD & $32.1 \pm 5.0$ \\
\hline Median (IQR) & $30(28-38)$ \\
\hline \multicolumn{2}{|l|}{ Tumor characteristics } \\
\hline \multicolumn{2}{|l|}{ Vertebral metastases, no./total } \\
\hline $2-3$ & $1 / 24$ \\
\hline More than 3 & $23 / 24$ \\
\hline \multicolumn{2}{|l|}{ Extravertebral skeletal metastases, no./total } \\
\hline None & $4 / 24$ \\
\hline 1 & $3 / 24$ \\
\hline 2 or 3 & $2 / 24$ \\
\hline More than 3 & $15 / 24$ \\
\hline \multicolumn{2}{|l|}{ Visceral metastases, no./total } \\
\hline None & $18 / 24$ \\
\hline 1 & $2 / 24$ \\
\hline 2 or 3 & $1 / 24$ \\
\hline More than 3 & $3 / 24$ \\
\hline
\end{tabular}

severe pain. Seventeen percent (4/23) of our patients were previously treated with RT only in an attempt for nonsurgical management but were nonresponsive. The types of surgery performed are depicted in Figure 2. Mean operation time was $246 \pm 114$ minutes. Median (IQR) blood loss was 800 (4501300) $\mathrm{mL}$ and was not associated with preoperative platelet count; 54\% (13/24) of patients received perioperative blood transfusion.

\section{Functional Outcomes}

Pain

The majority of our patients benefited from surgery in terms of pain reduction in the short term 
Table 2. Clinical presentation, indications leading to surgery, and surgical details.

\begin{tabular}{lc}
\hline Parameter & No./Total \\
\hline Clinical presentation & \\
Symptoms present at admission, no./total & \\
Pain & $(6 / 24 / 24$ \\
Neurological deficit (sensory/motor deficit, bowel/bladder dysfunction) & $16(4-60)$ \\
$\quad$ Bowel/bladder dysfunction & $8(3-16)$ \\
No. of days from onset of first symptom until admission, median (interquartile range [IQR]) & $9 / 24$ \\
No. of days from onset of motor deficit or bowel/bladder dysfunction to surgery, median (IQR) & $15 / 24$ \\
Multiple myeloma (MM) diagnosis known & $14 / 23$ \\
MM newly diagnosed & $8 / 23$ \\
Main indication leading to surgery & $1 / 23$ \\
Rapid neurological deterioration with or without spinal cord compression (SCC), no./total & $0 / 23$ \\
Mechanical instability, no./total & $0 / 23$ \\
Stand-alone pain, no./total & $14 / 24$ \\
Stable neurodeficit, no./total & $10 / 24$ \\
Impending SCC, no./total & $20 / 24$ \\
Nature of surgery, no./total & $4 / 24$ \\
Priority &
\end{tabular}

(Wilcoxon signed-rank $P=.0010$ ) as well as in the long term (Wilcoxon signed-rank $P=.0003$ ).

\section{Ambulatory Status (ECOG)}

The difference in preoperative ECOG and ECOG at discharge was not statistically significant $(P=.2805)$.

\section{Neurological Status (ASIA)}

There was no statistically significant difference in ASIA scored between the following time points:

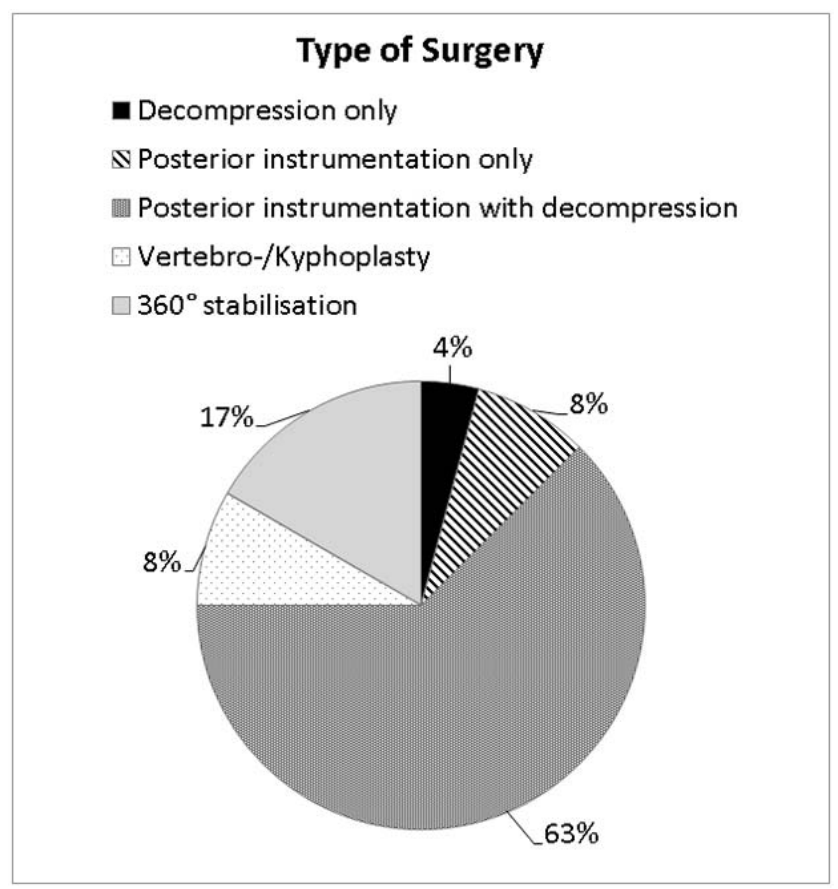

Figure 2. Type of surgery performed in all patients. preoperative and immediate postoperative $(P=$ .7809), preoperative and discharge $(P=.0790)$, and preoperative and last follow-up $(P=.2059)$. Overall, the neurological status worsened in $29 \%$ (7/ 24) of patients and remained unchanged in $63 \%(15 /$ 24). Of the 16 patients who presented with a neurological deficit, 13\% (2/16) improved.

\section{Predisposing Factors for Neurological Deterioration (ASIA)}

Potential predisposing factors of neurological deterioration from preoperative time point to discharge include SCC (OR: 0.243; 95\% CI: 1.015.86; $P=.0482$ ), Bilsky score (OR: 23.00; 95\% CI: 3.11-170.30; $P=.0021)$, preoperative Karnofsky Performance Scale (KPS) $\leq 50$ (OR: 8.13; 95\% CI: $1.11-59.21 ; P=.0387)$, and the presence of motor deficit or bowel/bladder dysfunction (OR: 37.50; 95\% CI: 2.88-508.47; $P=.0064)$.

\section{Factors Influencing OS}

A higher Tomita score strongly influenced OS (Hazard ratio $[\mathrm{HR}]=1.56 ; 95 \% \mathrm{CI}: 1.07-2.27 ; P=$ $.0213){ }^{34}$ For every additional 1-point increase in $\mathrm{CCI}$, the risk of death increased by $36 \%(\mathrm{HR}=1.36$; 95\% CI: $1.00-1.85 ; P=.0494)$. Patients with the RISS stage 3 lived 17 months compared to 70 months among patients with R-ISS stage 1 or $2(\mathrm{HR}=4.07$; 95\% CI: $1.07-15.50 ; P=.0393)$. Patients with preoperative motor deficit or bowel/bladder dysfunction lived for 5 months as compared to 70 


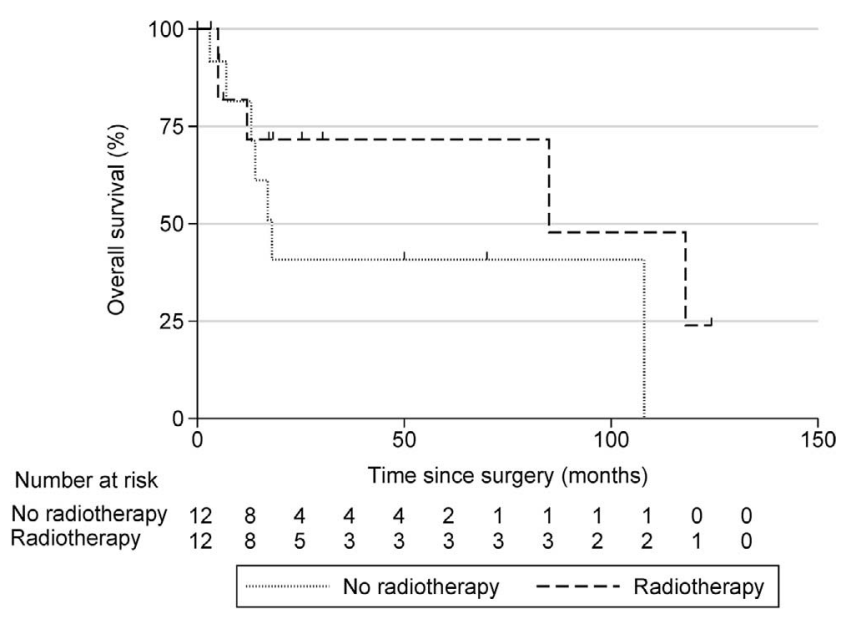

Figure 3. Kaplan-Meier curve for overall survival in patients who received or did not receive radiotherapy.

months among patients without these symptoms $(\mathrm{HR}=30.50 ; 95 \% \mathrm{CI}: 3.46-270 ; P=.0021)$. Patients who had ASIA grade C, D, or E had a median OS duration of 50 months as compared to 6 months among patients with ASIA grade $\mathrm{A}$ or $\mathrm{B}(\mathrm{HR}=$ $0.21 ; 95 \%$ CI: 0.05-0.95; $P=.0432$ ). Improvement in ASIA score postoperatively did not predict improved survival. However, deterioration of ASIA score at discharge significantly worsened survival $(\mathrm{HR}=12.65 ; 95 \% \mathrm{CI}: 2.37-67.61 ; P=.0030)$. None of the following factors had an association with OS: age, operation duration, blood loss, SINS, KPS, ECOG, Bilsky score, presence of SCC, pathological fracture as indication, American Society of Anesthesiologists status, elective versus emergency surgery, open versus MIS, number of vertebrae instrumented, preoperative steroids, RT (Figure 3), VAS, preoperative white blood cell (WBC) count, and albumin.

Complications and Predisposing Factors, Implant Failure, and Tumor Recurrence

Early complications ( $<3$ months after surgery) occurred in $83 \%(20 / 24)$ of our patients (Figure 4$)$. There was $1(4 \%$ [1/24]) case of asymptomatic cement extrusion. There was 1 local tumor recurrence observed and revised during the index hospital stay. Early revisions were recorded in 3 cases (due to

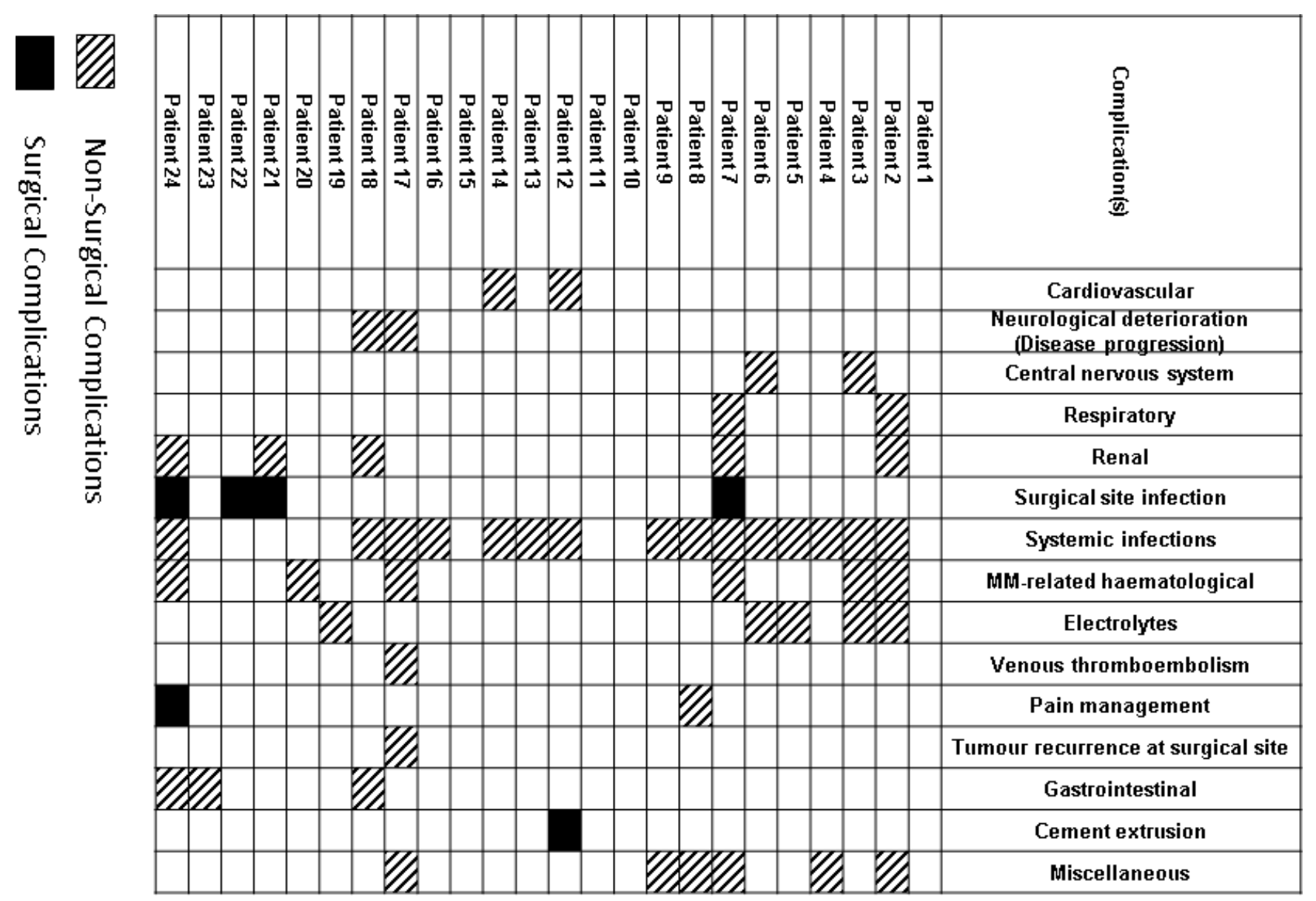

Figure 4. Complications $<3$ months from surgery. 
tumor recurrence or SSI). No implant failure was observed within 3 months. We found no association of early infective complications with preoperative level of WBC, diabetes, preoperative steroids, Bilsky score, SCC, ChT/RT, or number of instrumented levels. The most common complication was systemic infections $(63 \%$ [15/24]).

Late implant failure ( $>3$ months after surgery) was noted in $17 \%(4 / 24)$ of patients, where 3 were asymptomatic $^{35}$ and none of them required revision. There was an additional tumor recurrence and 2 additional revisions (due to implant infection) after 3 months.

\section{DISCUSSION}

The advent of newer AMD has resulted in prolonged survival, ${ }^{23,36}$ thereby stressing the importance of supportive care and surgical interventions. Because of the dearth of the literature, indications for surgery in MM patients with SIS remain debatable, and clear standards for surgical treatments are yet to be established. ${ }^{9,23,27}$

Conventionally, patients with SIS are treated with RT in conjunction with AMD. ${ }^{4,18}$ Surgical management is rarely indicated in these patients, as the MM lesions are highly sensitive to RT and AMD. ${ }^{4}$ Particularly, patients who experience ongoing mechanical pain due to (impending) fractures can be successfully treated with either percutaneous vertebral augmentation techniques or open surgical stabilization with decompression. ${ }^{4,16,37-40}$ According to the NOMS decision framework, high-grade epidural SCC and mechanical instability are particularly promising indications for surgery. ${ }^{25} \mathrm{We}$ scrutinized the indications leading to surgery. Our results show that out of 23 patients with traceable surgical indications, rapid neurological deterioration with or without SCC $(61 \%)$ was the main indication that had led to urgent surgical decompression. The second most common indication for surgery was mechanical instability $(35 \%)$, where all of these patients suffered from moderate to severe pain and showed a SINS between 9 and 13 .

The effectiveness of surgical intervention in alleviating pain and improving the quality of life of spine tumor patients has been substantiated in the literature. ${ }^{6,24,28,41,42}$ Since the beneficial effects of RT on pain control may require several days to a few weeks, surgery can be considered as an immediate alternative for pain management. ${ }^{43,44}$ We observed that the majority of patients benefited from surgery in terms of pain reduction, which lasted in the long term, when patients were assessed at their final follow-up.

The mainstay of treatment for SCC and severe pain due to spinal lesions in $\mathrm{MM}$ patients is RT. ${ }^{9,45,46}$ However, we observed that $50 \%$ of our patients were treated by surgery without adjuvant RT. This is because three-quarters of these patients showed a good response when treated with single-/ multiagent AMD with or without ASCT. In the remaining $25 \%$ ( 3 patients), the reason for not having undergone adjuvant RT was not traceable.

The overall 10-year survival rates in our series was $30.7 \%$, which is consistent with the current literature. ${ }^{23}$ Amelot et $\mathrm{al}^{47}$ found that spine surgical prognosis scores are not accurate in MM patients. Of the several survival prediction scores, only the Tomita score showed a significant correlation in our study. Ambulatory status (ECOG, KPS) was not found to be associated with OS, although the literature states that postoperative ambulation is a positive prognostic factor. ${ }^{48-51}$ However, we observed that any neurological deterioration was strongly associated with worse survival, especially in the presence of motor deficit or bowel/bladder dysfunction. The percentage of postoperative neurological recovery varies widely in the literature, where some report drastic improvement ${ }^{6,16,26,27,52}$ and others observed modest recovery. ${ }^{47,53,54}$ In our study, neurological function (ASIA) remained unchanged in 15 of our patients who presented with or without neurological deficit, improved in 2 , and worsened in 7.

Perioperative complications in spinal tumor surgery are relatively high with an average of $26.9 \%$ (range: $5.3 \%-76.2 \%$ ), ${ }^{55,56}$ where SSI represents one of the most common ones. ${ }^{56-58}$ The exact incidence of SSI following spinal tumor surgery averages $10.22 \%$ (range: $3.51 \%-20 \%$ ). ${ }^{56,58}$ Park et $\mathrm{al}^{59}$ and Menendez et $\mathrm{al}^{60}$ have mentioned that patients with MM are at an increased risk for early postoperative complications following surgical treatment. In our study, we recorded complications over a relatively longer period of 3 months and observed that $83 \%$ of patients encountered early postoperative complications. Twenty-one percent of our patients experienced surgical-related (SSI [17\%] and cement extrusion [4\%]) complications. In the literature, several risk factors have been proposed for SSI. ${ }^{56-58}$ We observed no obvious factors predisposing to infective complications (ie, RT/ 
AMD therapy, higher number of instrumented levels, diabetes, or use of steroids). However, we observed that patients undergoing emergency surgery developed more infective complications than those undergoing elective surgery $(P=.0523)$.

Tumor recurrence in MM patients ranges between $6 \%$ and $11 \%$ in the literature. ${ }^{54,61} \mathrm{We}$ observed local tumor recurrences in $8 \%(2 / 24)$ within 1 year postoperatively. Both of them had received RT between 6 and 8 weeks after surgery, which is much later compared to an average of 3.3 weeks among those patients without recurrence. The National Comprehensive Cancer Network guidelines suggest that the time gap should not exceed 6 weeks between surgery and the commencement of adjuvant RT. ${ }^{62}$

\section{Limitations}

The major limitation of our study is the small sample size, which made multivariate analysis not appropriate. The small sample size may be attributed to the small number of MM patients who qualify for surgery. Other limitations include the retrospective study design and the lack of a nonsurgical study control group. We have derived most of our understanding of epidemiology and outcomes of MM based on small case series and existing literature. We have compensated for this limitation by following up with our patients for a median of 7 years, which is relatively longer than most studies in the literature. ${ }^{24,27,63-66}$

\section{CONCLUSIONS}

In our study, we observed that a sudden onset of neurological deterioration had led predominantly to surgery. Our patients benefited from surgical treatment in terms of good short- and long-term pain reduction. There were no obvious factors predisposing to infective complications. Neurological deterioration, especially in the presence of motor deficit or bowel/bladder dysfunction, significantly reduced OS. We thus conclude that surgery is a valuable option for MM patients with SIS who present with rapid neurological deterioration with or without SCC and/or mechanical instability.

\section{ACKNOWLEDGMENTS}

We are thankful to the Swiss Society of Orthopaedics and Traumatology ("Stipendienfonds Swiss Orthopaedics") for supporting this project. We would also like to thank Dr Balamurugan Vellayappan (radiation oncologist, Department of Radiation Oncology, National University Cancer Institute, Singapore) for his support in retrieving details of radiotherapy. We would also like to thank Sridharan Alathur Ramakrishnan and Sirisha Madhu for the support with editing the manuscript.

\section{REFERENCES}

1. Christoulas D, Terpos E, Dimopoulos MA. Pathogenesis and management of myeloma bone disease. Expert Rev Hematol. 2009;2(4):385-398.

2. Terpos E, Christoulas D, Gavriatopoulou M. Biology and treatment of myeloma related bone disease. Metabolism. 2018;80:80-90.

3. Palumbo A, Anderson K. Multiple myeloma. New Engl J Med. 2011;364(11):1046-1060.

4. Bilsky MH, Azeem S. Multiple myeloma: primary bone tumor with systemic manifestations. Neurosurg Clin $N$ Am. 2008;19(1):31-40.

5. Dickman CA, Fehlings M, Gokaslan ZL. Spinal Cord and Spinal Column Tumors: Principles and Practice. New York, NY: Thieme; 2006.

6. Chataigner H, Onimus M, Polette A. Surgical treatment of myeloma localized in the spine. Rev Chir Orthop Reparatrice Appar Mot. 1998;84(4):311-318.

7. Chi JH, Bydon A, Hsieh $\mathrm{P}$, et al. Epidemiology and demographics for primary vertebral tumors. Neurosurg Clin $N$ Am. 2008;19(1):1-4.

8. Edwards CM, Zhuang J, Mundy GR. The pathogenesis of the bone disease of multiple myeloma. Bone. 2008;42(6):10071013.

9. Quidet M, Zairi F, Boyle E, et al. Evaluation of the relevance of surgery in patients with multiple myeloma harboring symptomatic spinal involvement: a retrospective case series. World Neurosurg. 2018;114:e356-e365.

10. Terpos E, Berenson J, Raje N, et al. Management of bone disease in multiple myeloma. Expert Rev Hematol. 2014;7(1):113-125.

11. Kyle RA. Multiple myeloma: review of 869 cases. Mayo Clin Proc. 1975;50(1):29-40.

12. Kyle RA, Rajkumar SV. Multiple myeloma. New Engl J Med. 2004;351(18):1860-1873.

13. Lecouvet FE, Vande Berg BC, Maldague BE, et al. Vertebral compression fractures in multiple myeloma. Part I. Distribution and appearance at MR imaging. Radiology. 1997;204(1):195-199.

14. Benson WJ, Scarffe JH, Todd I, et al. Spinal-cord compression in myeloma. Br Med J. 1979;1(6177):1541-1544.

15. Dispenzieri A, Kyle RA. Neurological aspects of multiple myeloma and related disorders. Best Prac Res Clin Haematol. 2005;18(4):673-688.

16. Flouzat-Lachaniette C-H, Allain J, Roudot-Thoraval F, et al. Treatment of spinal epidural compression due to hematological malignancies: a single institution's retrospective experience. Eur Spine J. 2013;22:(3)548-555.

17. Gokaraju K, Butler JS, Benton A, et al. Multiple 
myeloma presenting with acute bony spinal cord compression and mechanical instability successfully managed nonoperatively. Spine J. 2016;16(8):e567-e570.

18. Molloy S, Lai M, Pratt G, et al. Optimizing the management of patients with spinal myeloma disease. $\mathrm{Br} J$ Haematol. 2015;171(3):332-343.

19. Wallington M, Mendis S, Premawardhana U, et al. Local control and survival in spinal cord compression from lymphoma and myeloma. Radiother Oncol. 1997;42(1):43-47.

20. Costa L, Badia X, Chow E, et al. Impact of skeletal complications on patients' quality of life, mobility, and functional independence. Support Care Cancer. 2008;16(8):879889.

21. Ontario HQ. Vertebral augmentation involving vertebroplasty or kyphoplasty for cancer-related vertebral compression fractures: a systematic review. Ontario Health Technol Assess Ser. 2016;16(11):1-202.

22. Saad F, Lipton A, Cook R, et al. Pathologic fractures correlate with reduced survival in patients with malignant bone disease. Cancer. 2007;110(8):1860-1867.

23. Foundation SsCotCMWGotIM. Consensus on surgical management of myeloma bone disease. Orthop Surg. 2016;8(3):263-269.

24. Utzschneider S, Schmidt H, Weber P, et al. Surgical therapy of skeletal complications in multiple myeloma. Int Orthop. 2011;35(8):1209-1213.

25. Bilsky M, Smith M. Surgical approach to epidural spinal cord compression. Hematol Oncol Clin. 2006;20(6):1307-1317.

26. Denaro V, Denaro L, Albo E, et al. Surgical management of spinal fractures and neurological involvement in patients with myeloma. Injury. 2016;47(4):S49-S53.

27. Zadnik PL, Goodwin CR, Karami KJ, et al. Outcomes following surgical intervention for impending and gross instability caused by multiple myeloma in the spinal column. J Neurosurg Spine. 2015;22(33):301-309.

28. Dürr HR, Wegener B, Krödel A, et al. Multiple myeloma: surgery of the spine: retrospective analysis of 27 patients. Spine. 2002;27(3):320-324.

29. Fahed Z, Marie-Helene V, Patrick D, et al. Management of neoplastic spinal tumors in a spine surgery care unit. Clin Neurol Neurosurg. 2015;128:35-40.

30. Nucci M, Anaissie E. Infections in patients with multiple myeloma in the era of high-dose therapy and novel agents. Clin Infect Dis. 2009;49(8):1211-1225.

31. Pascal-Moussellard H, Broc G, Pointillart V, et al. Complications of vertebral metastasis surgery. Eur Spine J. 1998;7(6):438-444.

32. Bilsky MH, Laufer I, Fourney DR, et al. Reliability analysis of the epidural spinal cord compression scale. $J$ Neurosurg Spine. 2010;13(3):324-328.

33. Fisher CG, DiPaola CP, Ryken TC, et al. A novel classification system for spinal instability in neoplastic disease: an evidence-based approach and expert consensus from the Spine Oncology Study Group. Spine. 2010;35(22):E1221E1229.

34. Tomita K, Kawahara N, Kobayashi T, et al. Surgical strategy for spinal metastases. Spine. 2001;26(3):298-306.

35. Kumar N, Patel R, Wadhwa AC, et al. Basic concepts in metal work failure after metastatic spine tumour surgery. Eur Spine J. 2018;27(4):806-814.
36. Richardson PG, Mitsiades C, Schlossman R, et al. New drugs for myeloma. Oncologist. 2007;12(6):664-689.

37. Cotten A, Dewatre F, Cortet B, et al. Percutaneous vertebroplasty for osteolytic metastases and myeloma: effects of the percentage of lesion filling and the leakage of methyl methacrylate at clinical follow-up. Radiology. 1996;200(2):525530 .

38. Donnarumma P, Tarantino R, Rullo M, et al. Surgery for vertebral involvement in Multiple Myeloma. J Neurosurg Sci. 2018;62(1):10-15.

39. Dudeney S, Lieberman I, Reinhardt M, et al. Kyphoplasty in the treatment of osteolytic vertebral compression fractures as a result of multiple myeloma. J Clin Oncol. 2002;20(9):2382-2387.

40. Hentschel SJ, Burton AW, Fourney DR, et al. Percutaneous vertebroplasty and kyphoplasty performed at a cancer center: refuting proposed contraindications. J Neurosurg Spine. 2005;2(4):436-440.

41. Fürstenberg C, Wiedenhöfer B, Gerner H, et al. The effect of early surgical treatment on recovery in patients with metastatic compression of the spinal cord. J Bone Joint Surg Br. 2009;91(2):240-244.

42. Patchell RA, Tibbs PA, Regine WF, et al. Direct decompressive surgical resection in the treatment of spinal cord compression caused by metastatic cancer: a randomised trial. Lancet 2005;366(9486):643-648.

43. De Felice F, Piccioli A, Musio D, et al. The role of radiation therapy in bone metastases management. Oncotarget. 2017;8(55):25691-25699.

44. Lutz S. The role of radiation therapy in controlling painful bone metastases. Curr Pain Headache Rep. 2012;16(4):300-306.

45. Rades D, Conde-Moreno AJ, Cacicedo J, et al. Excellent outcomes after radiotherapy alone for malignant spinal cord compression from myeloma. Radiol Oncol. 2016;50(3):337-340.

46. Talamo G, Dimaio C, Abbi KK, et al. Current role of radiation therapy for multiple myeloma. Front Oncol. 2015;5:40. 10.3389/fonc.2015.00040.

47. Amelot A, Cristini J, Salaud C, et al. Overall survival in spine myeloma metastases: difficulties in predicting with prognostic scores. Spine. 2017;42(6):400-406.

48. Hirabayashi H, Ebara S, Kinoshita T, et al. Clinical outcome and survival after palliative surgery for spinal metastases: palliative surgery in spinal metastases. Cancer. 2003;97(2):476-484. 339.

49. Raab MS. Multiple myeloma. Lancet. 2009;374(9686):324

50. Raje N, Roodman GD. Advances in the biology and treatment of bone disease in multiple myeloma. Clin Cancer Res. 2011;17(6):1278-1286.

51. Yang SB, Cho W, Chang U-K. Analysis of prognostic factors relating to postoperative survival in spinal metastases. $J$ Korean Neurosurg Soc. 2012;51(3):127-134.

52. Shen J, Du X, Zhao L, et al. Comparative analysis of the surgical treatment results for multiple myeloma bone disease of the spine and the long bone/soft tissue. Oncol Lett. 2018;15(6):10017-10025.

53. Okacha N, Chrif E, Brahim E, et al. Extraosseous epidural multiple myeloma presenting with thoracic spine compression. Joint Bone Spine. 2008;75(1):70-72.

54. Zeifang F, Zahlten-Hinguranage A, Goldschmidt H, et 
al. Long-term survival after surgical intervention for bone disease in multiple myeloma. Ann Oncol. 2005;16(2):222-227.

55. Lee BH, Park J-O, Kim H-S, et al. Perioperative complication and surgical outcome in patients with spine metastases: retrospective 200-case series in a single institute. Clin Neurol Neurosurg. 2014;122:80-86.

56. Luksanapruksa P, Buchowski JM, Zebala LP, et al. Perioperative complications of spinal metastases surgery. Clin Spine Surg. 2017;30(1):4-13.

57. Demura S, Kawahara N, Murakami H, et al. Surgical site infection in spinal metastasis: risk factors and countermeasures. Spine. 2009;34(6):635-639.

58. Sebaaly A, Shedid D, Boubez G, et al. Surgical site infection in spinal metastasis: incidence and risk factors. Spine J. 2018;18(8):1382-1387.

59. Park KJ, Menendez ME, Mears SC, et al. Patients with multiple myeloma have more complications after surgical treatment of hip fracture. Geriatr Orthop Surg Rehabil. 2016;7(3):158-162.

60. Menendez ME, Park KJ, Barnes CL. Early postoperative outcomes after total joint arthroplasty in patients with multiple myeloma. J Arthroplasty. 2016;31(8):1645-1648.

61. Hannisdal E, Kildahl-Andersen O, Grøttum K, et al. Prognostic factors in multiple myeloma in a population-based trial. Eur J Haematol. 1990;45(4):198-202.

62. Divi V, Chen MM, Hara W, et al. Reducing the time from surgery to adjuvant radiation therapy: an institutional quality improvement project. Otolaryngol Head Neck Surg. 2018;159(1):158-165.

63. Bataille R, Harousseau J. Multiple myeloma. New Engl J Med. 1997;336(23):1657-1664.

64. Chao M, Gibbs P, Wirth A, et al. Radiotherapy in the management of solitary extramedullary plasmacytoma. Intern Med J. 2005;35(4):211-215.
65. Knobel D, Zouhair A, Tsang RW, et al. Prognostic factors in solitary plasmacytoma of the bone: a multicenter Rare Cancer Network study. BMC Cancer. 2006;6(1):118. 10. 1186/1471-2407-6-118.

66. Ozsahin M, Tsang RW, Poortmans P, et al. Outcomes and patterns of failure in solitary plasmacytoma: a multicenter Rare Cancer Network study of 258 patients. Int J Radiat Oncol Biol Physics. 2006;64(1):210-217.

Disclosures and COI: This project has been supported by the Swiss Society of Orthopaedics and Traumatology ("Stipendienfonds Swiss Orthopaedics"). Ethics approval was obtained by National Healthcare Group (NHG), Domain Specific Review Board (DSRB) Ref. No. 2018/00950.

Corresponding Author: Dr Helena Milavec, MD, Spine Unit, Department of Orthopaedic Surgery and Traumatology, Inselspital, Bern University Hospital, Freiburgstrasse 18, CH-3010 Bern, Switzerland. Phone: +41 3163222 13; Fax: +41 31 63236 00; Email: helena.milavec@insel.ch.

Published 11 November 2020

This manuscript is generously published free of charge by ISASS, the International Society for the Advancement of Spine Surgery. Copyright (c) 2020 ISASS. To see more or order reprints or permissions, see http://ijssurgery.com. 